\title{
Dual Function of UV/Ozone Plasma-Treated Polymer in Polymer/Metal Hybrid Electrodes and Semitransparent Polymer Solar Cells
}

Wenhao Zheng, Yuanbao Lin, Yangdong Zhang, Junyu Yang, Zuosheng Peng, Alei Liu, Fengling Zhang and Lintao Hou

The self-archived postprint version of this journal article is available at Linköping University Institutional Repository (DiVA):

http://urn.kb.se/resolve?urn=urn:nbn:se:liu:diva-144261

N.B.: When citing this work, cite the original publication.

Zheng, W., Lin, Y., Zhang, Y., Yang, J., Peng, Z., Liu, A., Zhang, F., Hou, L., (2017), Dual Function of UV/Ozone Plasma-Treated Polymer in Polymer/Metal Hybrid Electrodes and Semitransparent Polymer Solar Cells, ACS Applied Materials and Interfaces, 9(51), 44656-44666.

https://doi.org/10.1021/acsami.7b14395

Original publication available at:

https://doi.org/10.1021/acsami.7b14395

Copyright: American Chemical Society

http://pubs.acs.org/ 


\section{Dual Function of UV/Ozone Plasma-Treated Polymer in Polymer/Metal Hybrid Electrodes and Semitransparent Polymer \\ Solar Cells}

Wenhao Zheng, ${ }^{\dagger}$ Yuanbao Lin, ${ }^{\dagger}$ Yangdong Zhang, ${ }^{\dagger}$ Junyu Yang, ${ }^{\dagger}$ Zuosheng Peng, ${ }^{\dagger}$ Alei Liu, ${ }^{\dagger}$ Fengling Zhang, ${ }^{\dagger,},{ }^{*}$ and Lintao Hou ${ }^{\dagger}, *$

$\dagger$ Guangdong Provincial Key Laboratory of Optical Fiber Sensing and Communications, Guangzhou Key Laboratory of Vacuum Coating Technologies and New Energy Materials, Siyuan Laboratory, Department of Physics, Jinan University, Guangzhou 510632, PR China.

$\S$ Biomolecular and Organic Electronics, Department of Physics, Chemistry and Biology (IFM), Linköping University, SE-581 83 Linköping, Sweden.

KEYWORDS: polymer/metal hybrid electrode, ITO-free, polymer solar cells, semitransparent, PFN/Ag 


\section{ABSTRACT:}
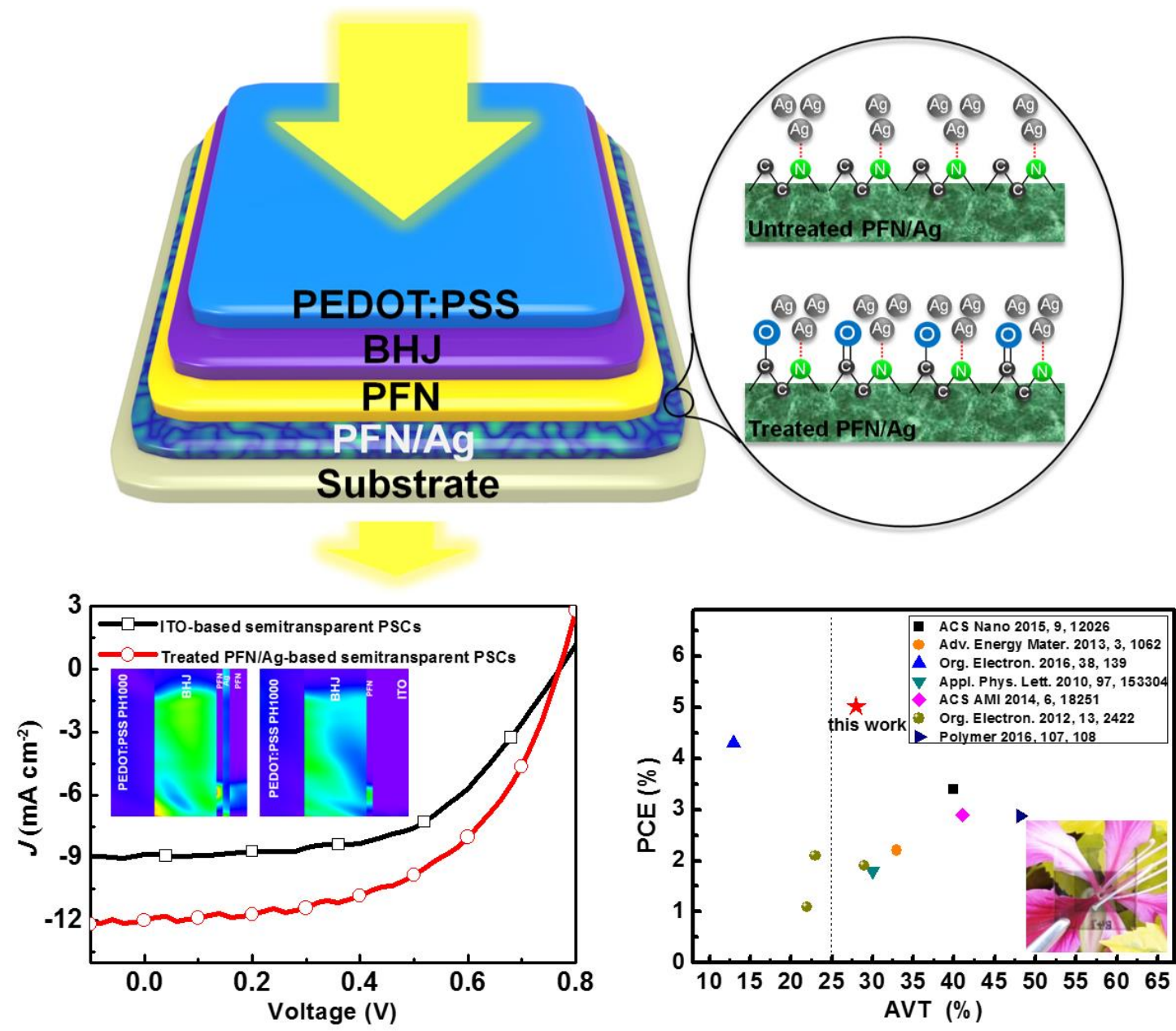

In this work, high performance inverted indium tin oxide (ITO)-free semitransparent polymer solar cells (PSCs) are comprehensively investigated using a novel polymer/metal hybrid transparent electrode. The electrical and optical characteristics of hybrid electrodes are significantly enhanced by introducing UV/ozone plasma treatment on the polymer poly[(9,9-bis(3'-(N,N-dimethylamino)propyl)-2,7-fluorene)-alt-2,7-(9,9-dioctylfluore ne)] (PFN), which is functioned as both a seed layer for ultrathin Ag metal electrode and an optical spacer for transparent devices. The optimized sheet resistance of PFN/Ag (12 nm) hybrid electrode is only half of the commercial ITO $\left(9.4 \mathrm{Ohm} \mathrm{sq}^{-1}\right.$ 
vs. $20.0 \mathrm{Ohm} \mathrm{sq}^{-1}$ ) and the high wavelength-dependent reflectance of hybrid electrode helps to increase the ITO-free device short-circuit current density. Furthermore, the interface property between PFN and ultrathin Ag is analyzed in detail and the optical field distribution is calculated for comparison. A high power conversion efficiency of $5.02 \%$, which is increased by $35 \%$ compared with that of ITO-based device, is achieved in the ITO-free semitransparent device in conjunction with an excellent average visible transmittance above $28 \%$ that is higher than the benchmark of $25 \%$ for power-generating window, indicating its great potential in building integrated photovoltaic systems in the future. Furthermore, the strategy is successfully developed to other polymer systems, suggesting the universal applicability for plastic electronics.

\section{INTRODUCTION}

Roll-to-roll compatible polymer solar cells (PSCs) are considered as potential candidates for the next generation of clean electricity because they possess unique advantages, such as solution processing, high throughput, mechanical flexibility, light weight and low cost, etc. ${ }^{1-4}$ The sensitivity to low light intensity and orientation of the sunlight as well as less light pollution make PSCs well-suited for building integrated photovoltaic (BIPV) systems. ${ }^{5}$ It is well known that the thickness of bulk heterojunction (BHJ) active layer in PSCs is typically in the range of $100 \mathrm{~nm}$, which permits nearly half of the sunlight to pass through. Therefore, it is favorable to employ semitransparent $\mathrm{BHJ}$ in power-generating windows for modulating light transmittance and generating electricity simultaneously. 
Generally the performance of indium tin oxide (ITO)-based semitransparent PSCs is mainly limited by incomplete photon absorption due to the weak microcavity effect, ${ }^{8}$ i.e. ITO allows the unabsorbed photons easily escaping from the device. ${ }^{9-16}$ Moreover, rising indium price, poor flexibility and high temperature processing make exploring alternative electrodes to ITO urgent. ${ }^{17-22}$ So far, several alternative electrodes have been developed, such as carbon-based electrodes (carbon nanotubes and graphene) and metallic nanostructure electrodes (nanowires, metal grids and meshes). ${ }^{23-25}$ Carbon-based electrodes have superior mechanical flexibility, but show high sheet resistance (carbon nanotubes: 100-1000 $\mathrm{Ohm} \mathrm{sq}^{-1}$ and graphene: 100-10000 Ohm sq ${ }^{-1}$ ) and complex preparation process. ${ }^{26-28}$ Metallic nanowires or grids have high transmittance $(>80 \%)$ with a low sheet resistance $\left(\mathrm{R}_{\text {sheet }}\right)(10-100$ Ohm $\mathrm{sq}^{-1}$ ), but the inhomogeneous connection, poor thermal stability and rough surface easily cause electrical shorts in device. ${ }^{29-32}$ In addition, ultrathin metal films have been reported as better candidates due to their easier processing and higher conductivity than above electrodes. ${ }^{33}$ However, the tradeoff between optical transparency and electrical conductivity is critical for the usage of ultrathin metal electrodes. Moreover, metallic nanoclusters or rough metal surface of ultrathin metals can result in strong light scattering and intense surface plasmonic absorption due to excitation of the localized plasmon resonance, which significantly reduces the film transmittance and hinders their applications in solar cells. ${ }^{34}$ Thus, employing a seed layer such as $\mathrm{Ca}, \mathrm{Au}$, and $\mathrm{Al}$ was introduced under the ultrathin metal electrode for achieving highly conductive and island-free transparent electrode. ${ }^{22}$ However, the 
seed layers reported can only reduce strong metal nanoparticle plasmonic absorption without regulating the light field. Exceptionally, dielectric/metal/dielectric (D/M/D) multilayers, such as $\mathrm{TeO}_{2} / \mathrm{Ag} / \mathrm{MoO}_{3}$ and $\mathrm{WO}_{3} / \mathrm{Ag} / \mathrm{WO}_{3}$, have been successfully employed to enhance the transmittance of thin metal films through adjusting the light field distribution; ${ }^{35-40}$ however, there are some indispensable drawbacks in D/M/D electrodes. For example, the dewetting between the thermally evaporated metal layer and the dielectric layer increases the percolation threshold of metal layer and thus greatly increases the sheet resistance $\left(\mathrm{R}_{\text {sheet }}\right) .{ }^{41}$ Furthermore, thermally evaporating very thick inorganic dielectric layers consumes huge energy, so the total manufacturing cost will be expensive for large-area D/M/D application. Using polymer instead of the inorganic dielectric materials or metallic materials can simultaneously solve above problems. ${ }^{42-46}$ The easily modified physic-chemical property of polymers makes the polymer/metal hybrid electrode exhibit a promising alternative to ITO with easy processing, high conductivity and transparency. However, despite these perceivable advantages, so far these polymers either functioned as the seed layer ${ }^{42,46}$ or as the optical spacer $^{43}$ individually, which limited the further application in transparent conductive electrodes. Actually, the reported polymers with the low refractive index cannot effectively regulate the light field distribution since the optical design requirements of semitransparent PSCs is much higher than those of opaque ones. ${ }^{16}$ At present, there have been very few works on integrating polymer materials in transparent conductive electrodes of ultrathin metal, especially utilizing polymer/metal hybrid electrode in semitransparent PSCs has never been reported, yet, 
deserving an in-depth study.

In this work, water/alcohol-soluble conjugated poly[(9,9-bis(3'-(N,N-dimethylamino)propyl)-2,7-fluorene)-alt-2,7-(9,9-dioctylfluore ne)] (PFN), which has dual functions of both an optical spacer and a seed layer, is chosen to be used in a novel polymer/metal hybrid transparent electrode (PFN/Ag). In order to enhance the wettability of the polymer film, UV/ozone plasma treatment is introduced into the polymer surface, prior to the deposition of $\mathrm{Ag}$ film. The improvements of optical and electrical properties in UV/ozone plasma-treated PFN/Ag $(10 \mathrm{~nm})$ electrode make the average visible transmittance (AVT) increase from 39 to $58 \%$ and $\mathrm{R}_{\text {sheet }}$ decrease from $483 \mathrm{kOhm} \mathrm{sq}^{-1}$ to $29.4 \mathrm{Ohm} \mathrm{sq}^{-1}$. Furthermore, the inverted ITO-free semitransparent PSCs are fabricated based on the PFN/Ag electrode with a ternary solute system of donor thieno[3,4-b]thiophene/benzo-dithiophene (PTB7) and acceptors of [6,6]-phenyl-C71-butyric acid methyl ester (PCBM[70]) and indene-C60 bisadduct (ICBA), followed by a solution-processed PEDOT:PSS electrode. A promising power conversion efficiency (PCE) of $5.02 \%$ with an AVT of $28 \%$ exceeding the transmittance benchmark of $25 \%$ for solar window is achieved, which is one of the highest PCEs among ITO-free semitransparent PSCs ever reported with fairly good transparency.

\section{RESULT AND DISCUSSION}

2.1. Optical and electrical properties of PFN/Ag electrode 
Considering the maximum transmittance of whole devices, it is necessary to take into account not only the electrode transmittance, but also the whole device transmittance involving the strong optical interference. Figure 1a exhibits the schematic structure of inverted ITO-free semitransparent PSCs used in this work with multilayers: PFN/Ag/PFN/active layer/PEDOT:PSS where the first PFN layer is used as both a polymeric metal nucleation inducer and an optical spacer, and the second PFN layer is used as an electron extraction layer. The chemical structures of PFN, PTB7, PCBM[70] and ICBA are shown in Figure 1b. To optimize the thickness of the PFN/Ag electrode in devices, optical calculation is employed without considering the nanoparticle plasmonic effect. ${ }^{12,13,36}$ As depicted in Figure 1c, the transmittance of the whole device is decreased with increasing the thicknesses of PFN and Ag layers at a human eye sensitive wavelength of $550 \mathrm{~nm}$. It is interesting that the device exhibits relatively high transmittance when PFN thickness is in the range of 44 46 nm regardless of the Ag thickness due to the reasonable optical field modulation effect of PFN. Therefore, the impact of Ag thickness on the optical properties of electrodes and devices is studied at a fixed $45 \mathrm{~nm}$ thickness of PFN. It should be pointed out the optimal thickness of PFN should be lowered to about $35 \mathrm{~nm}$ for the PFN/Ag bilayer transparent electrode if other layers of devices are not taken into account (Figure S1), which is generally ignored in many reported works. ${ }^{35,43}$ 


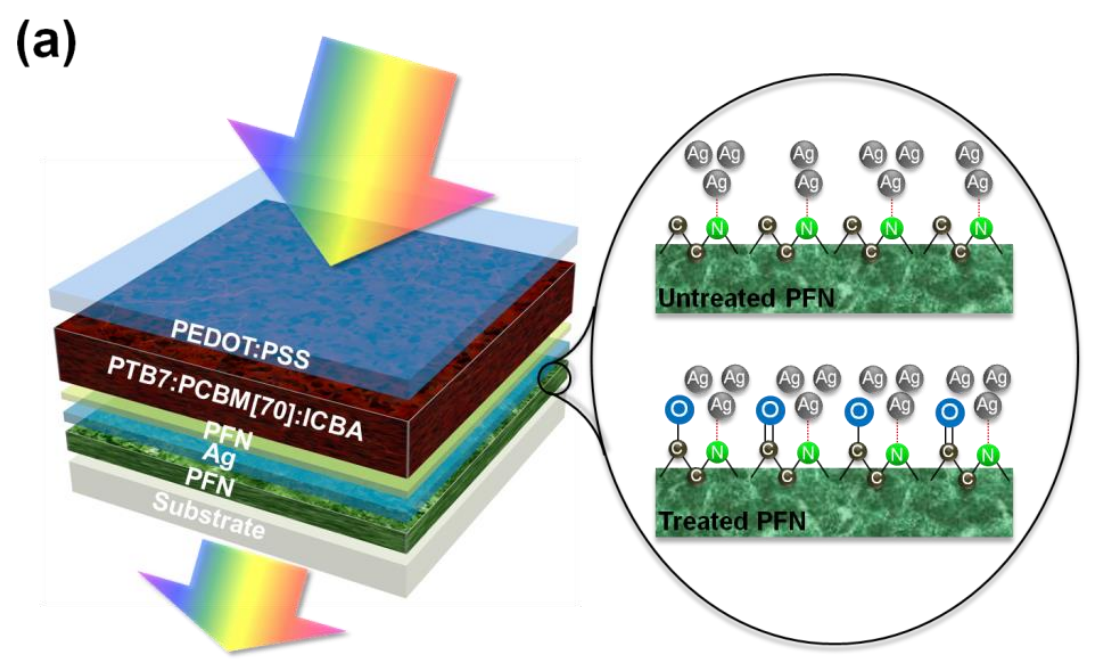

(b)
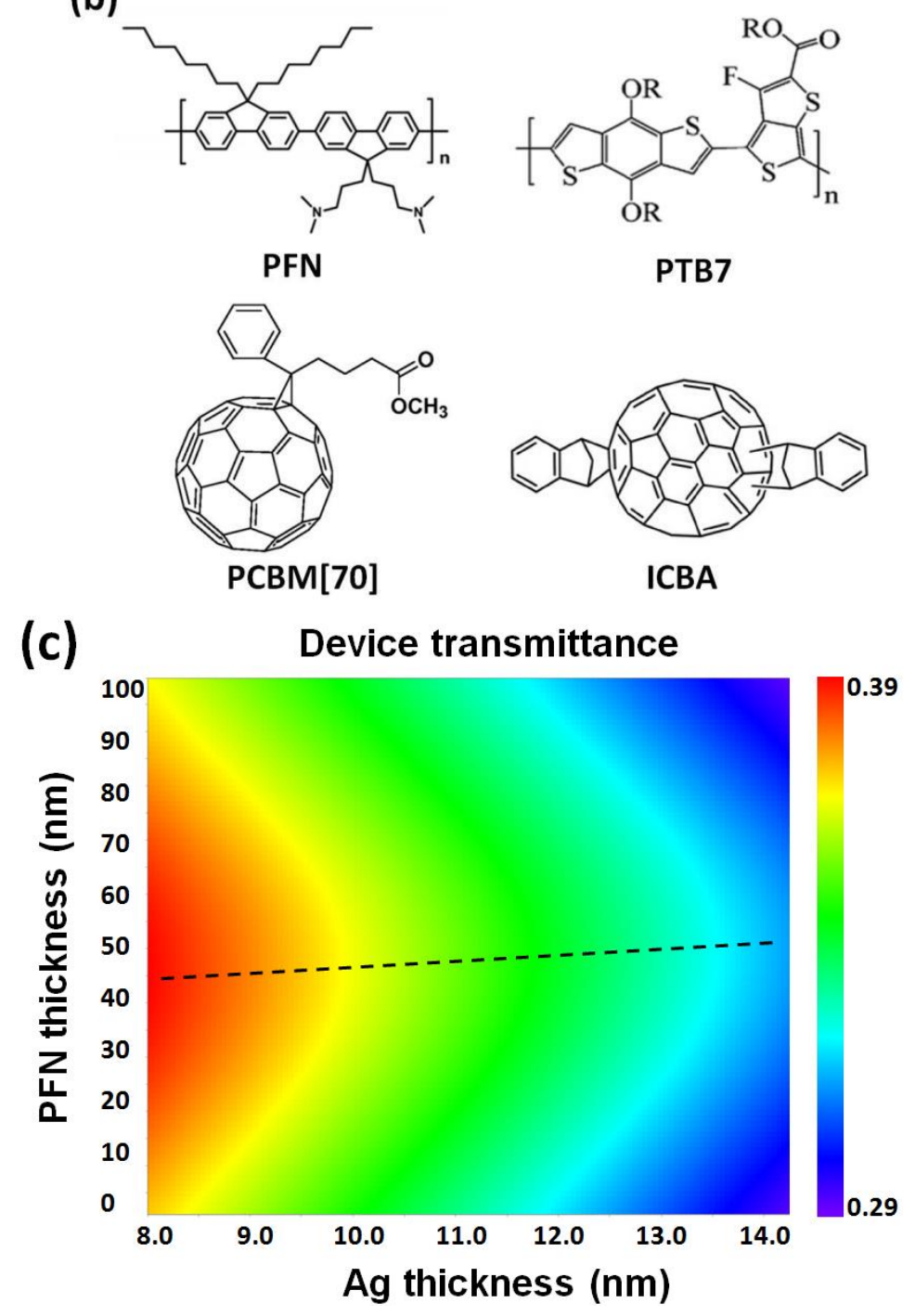

Figure 1. (a) Device architecture of semitransparent PSCs with incident and transmitted light. The right image shows the interaction of $\mathrm{Ag}$ atoms and PFN 
molecules. (b) Molecular structures of PFN, PTB7, PCBM[70] and ICBA. (c) 2D contour AVT image of semitransparent PSCs with the thickness change of $x$ and $y$ in glass/PFN $(y \mathrm{~nm}) / \operatorname{Ag}(x \mathrm{~nm})$ hybrid electrodes at a wavelength of $550 \mathrm{~nm}$. The approximate horizontal dash line shows the transmittance peak trend.

As shown in Figure 2a and Figure S2, the AVT of the bare Ag from 380 to $780 \mathrm{~nm}$ is first increased in the range of $\mathrm{Ag}$ thickness from 8 to $10 \mathrm{~nm}(30.4 \%$ vs. 37.6\%) then decreased from 10 to $12 \mathrm{~nm}(37.6 \%$ vs. $33.8 \%)$ due to the plasmonic absorption by $\mathrm{Ag}$ nanoparticles. For the PFN (45 nm)/Ag electrode without surface treatments, the AVT is further increased, especially for 8-nm-thick $\mathrm{Ag}(36.0 \%$ vs. 30.4\%) due to the strong inhibition of Ag nanoparticles plasmonic absorption. Since the light field is modulated by PFN with a high refractive index,${ }^{47}$ the transmission spectrum is shifted to the visible light wavelength (Figure 2a), which is advantageous to controlling and tuning optical absorption of active layers for semitransparent PSCs. Furthermore, it is worth noting that the UV/ozone plasma-treated PFN/Ag electrode exhibits a much higher AVT compared to bare $\mathrm{Ag}$ and untreated PFN/Ag electrodes. For example, the plasma-treated PFN/Ag $(10 \mathrm{~nm})$ electrode shows the best optical property with the highest AVT of 58.1\%, which is improved by $54.5 \%$ compared to that of the bare Ag $(10 \mathrm{~nm})(58.1 \%$ vs. $37.6 \%)$. In addition, the AVT difference between simulated and experimental results is much smaller in plasma-treated PFN/Ag electrodes than that in bare Ag or untreated PFN/Ag electrodes. Thus it is obvious that UV/ozone plasma treatment on PFN prior to ultrathin Ag evaporation is very useful to improve the 
optical property of PFN/Ag hybrid electrodes.

To find out the tendency of electrical performance of PFN/Ag electrodes, the $\mathrm{R}_{\text {sheet }}$ is measured using four-point probe with the modulations of $\mathrm{Ag}$ thickness or UV/ozone plasma power. As presented in Figure $2 b, R_{\text {sheet }}$ of the bare Ag, untreated $\mathrm{PFN} / \mathrm{Ag}$ and UV/ozone plasma-treated PFN/Ag is decreased with increasing $\mathrm{Ag}$ thickness. Compared to the 10-nm-thick bare Ag electrode with $\mathrm{R}_{\text {sheet }}$ up to $483 \mathrm{kOhm}$ $\mathrm{sq}^{-1}$, the PFN/Ag $(10 \mathrm{~nm})$ electrode without plasma treatment exhibits a lower $\mathrm{R}_{\text {sheet }}$ to $147.5 \mathrm{Ohm} \mathrm{sq}{ }^{-1}$, revealing that the interaction between $\mathrm{Ag}$ atoms and PFN molecules can greatly affect the electrical property of ultrathin Ag. Furthermore, The $\mathrm{R}_{\text {sheet }}$ of the plasma-treated PFN/Ag $(10 \mathrm{~nm})$ electrode is sharply decreased and eventually saturated to a value of $29.4 \mathrm{Ohm} \mathrm{sq}^{-1}$ with a high AVT of $58.1 \%$. The dependence of $R_{\text {sheet }}$ on UV/ozone plasma powers is also investigated, as shown in Figure 2c. The $\mathrm{R}_{\text {sheet }}$ of PFN/Ag (10 nm) electrodes is decreased from $147.5 \mathrm{Ohm} \mathrm{sq}^{-1}$ to $63.8 \mathrm{Ohm} \mathrm{sq}^{-1}$ with UV/ozone plasma power of $50 \mathrm{~W}$ performing on the PFN film, confirming that UV/ozone plasma treatment has a pronounced positive effect on reducing $R_{\text {sheet. }}$ Particular attention is paid to the fact that the $R_{\text {sheet }}$ of the plasma-treated PFN/Ag $(12 \mathrm{~nm})$ electrode at $350 \mathrm{~W}$ is much lower than that of the 165-nm-thick ITO (9.4 $\mathrm{Ohm} \mathrm{sq}^{-1}$ vs. $\left.20 \mathrm{Ohm} \mathrm{sq}^{-1}\right)$ with a fairly high AVT of 54.3\%. Thereby it is concluded that UV/ozone plasma-treated PFN allows the ultrathin Ag to own a reduced resistance and an elevated optical transmittance simultaneously. 
(a)

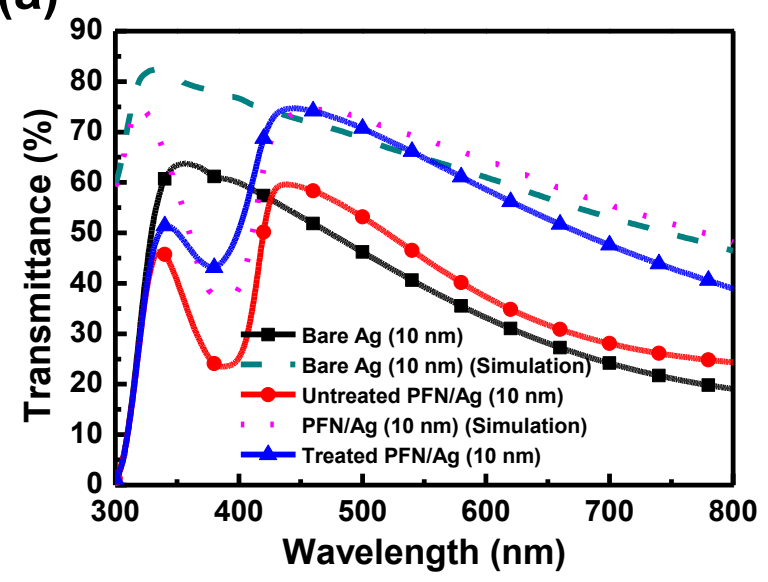

(b)

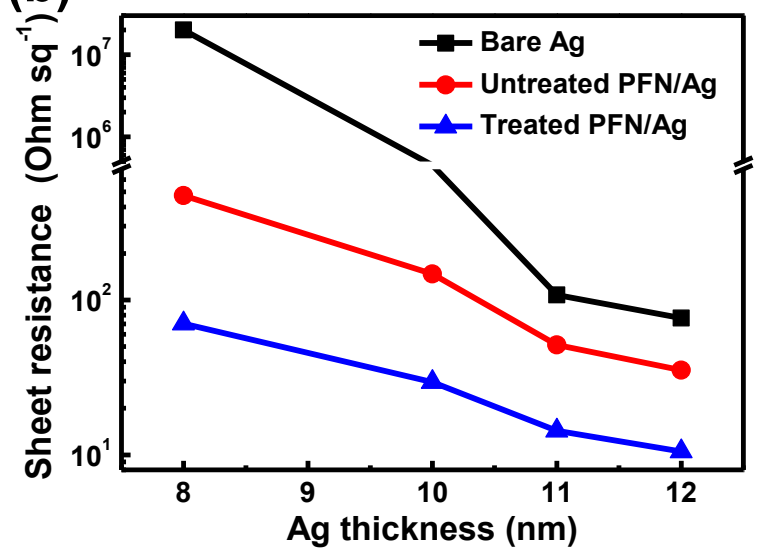

(c)

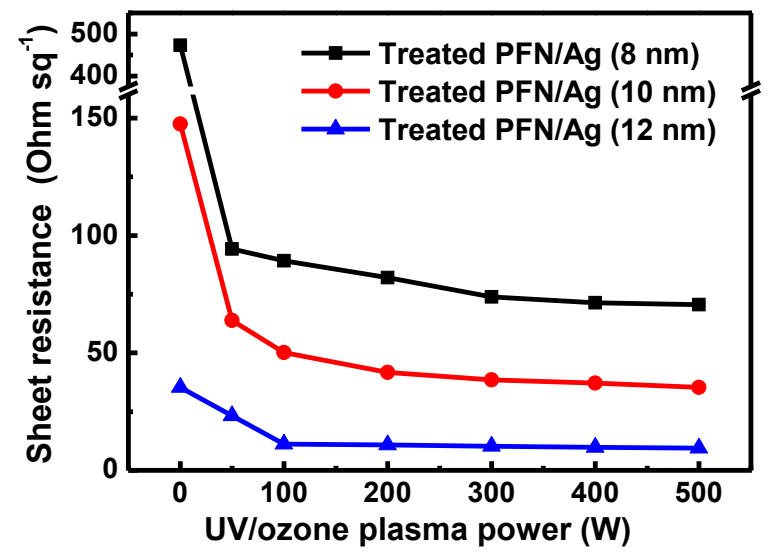

Figure 2. (a) Experimental and theoretical transmittance spectra of bare $\mathrm{Ag}(10 \mathrm{~nm})$, untreated PFN/Ag (10 nm) and plasma-treated PFN/Ag (10 nm) electrodes. (b) $R_{\text {sheet }}$ of bare Ag, PFN/Ag and plasma-treated PFN/Ag electrodes as a function of $\mathrm{Ag}$ thickness $(8,10,11$ and $12 \mathrm{~nm})$. The UV/ozone plasma power is $350 \mathrm{~W}$. (c) $\mathrm{R}_{\text {sheet }}$ of 
PFN/Ag $(8,10$ and $12 \mathrm{~nm})$ electrodes as a function of UV/ozone plasma power.

\subsection{Origin of optical and electrical enhancements in PFN/Ag electrode}

To understand the mechanism of the optical and electrical enhancements in PFN/Ag electrodes, the change of chemical composition at PFN/Ag interface is intensively studied by high-resolution X-ray photoelectron spectroscopy (XPS) measurements. Figure 3a,b present XPS spectra of bare $\mathrm{Ag}(2.5 \mathrm{~nm})$, untreated PFN, untreated PFN/Ag $(2.5 \mathrm{~nm})$ and plasma-treated PFN/Ag $(2.5 \mathrm{~nm})$ films. A negative chemical shift is found at the Ag $3 \mathrm{~d}$ core level, indicating that Ag atoms provide the empty orbit to other atoms. Furthermore, the emergence of $\mathrm{N}-\mathrm{Ag}$ groups reveals $\mathrm{N}$ atoms provide the electrons to the empty orbit of the Ag atoms. ${ }^{48-50}$ Thus it can be concluded that the functional amine groups of the water/alcohol-soluble conjugated PFN polymer offer unshared electron pairs to Ag atoms in form of coordinate bonds (as seen in the right image of Figure 1a). ${ }^{51}$ When UV/ozone plasma treatment is performed on the PFN film, the $\mathrm{C} 1 \mathrm{~s}$ and $\mathrm{O}$ 1s core level spectra of UV/ozone plasma-treated PFN/Ag are also changed compared to untreated PFN or PFN/Ag (2.5 $\mathrm{nm}$ ) without plasma treatment. As shown in Figure $3 \mathrm{c}, \mathrm{d}$, the $\mathrm{C} 1 \mathrm{~s}$ spectrum of the untreated PFN is composed of two components: the $\mathrm{C}-\mathrm{H}$ at a binding energy of 284.7 $\mathrm{eV}$ and the $\mathrm{C}-\mathrm{O}$ groups at $286.1 \mathrm{eV}$. The $\mathrm{O} 1 \mathrm{~s}$ spectrum of the untreated $\mathrm{PFN}$ is separated into two components: $\mathrm{O}=\mathrm{C}$ groups at a binding energy of $531.6 \mathrm{eV}$, and the O-C groups at a binding energy of $532.5 \mathrm{eV}$. With UV/ozone plasma treatment, the spectrum intensity of $\mathrm{C} 1 \mathrm{~s}$ is decreased but broadened to the high energy side, known 
as the attribution of hydroxyl, carbonyl, and carboxyl group formation. ${ }^{46,52}$ The $\mathrm{O} 1 \mathrm{~s}$ spectrum intensity is increased and the ratio of $\mathrm{C}=\mathrm{O} / \mathrm{C}-\mathrm{O}$ bonds is also enhanced with UV/ozone plasma treatment due to the generation of oxygen free radicals. It can be predicted that more oxygen polar groups $(\mathrm{C}=\mathrm{O}$ and $\mathrm{C}-\mathrm{O})$ would be produced on the PFN surface if UV/ozone plasma power is increased. In particular, since the polarity of $\mathrm{C}=\mathrm{O}$ bond is stronger than that of $\mathrm{C}-\mathrm{O}$ bond, the surface wettability of PFN layer is significantly changed from hydrophobic to hydrophilic after UV/ozone plasma treatment, which is consistent with the findings of the water contact angles of PFN layers with increasing the power of UV/ozone plasma treatment (Figure S3). ${ }^{53}$

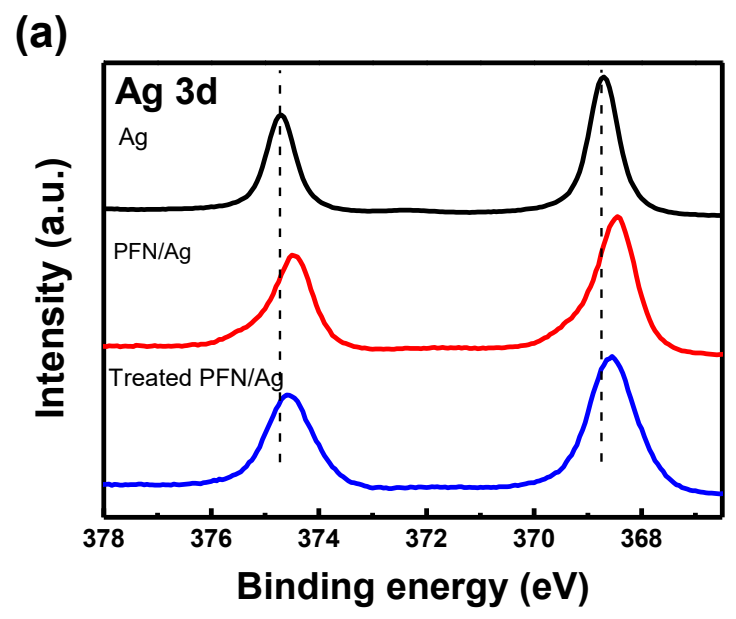

(b)

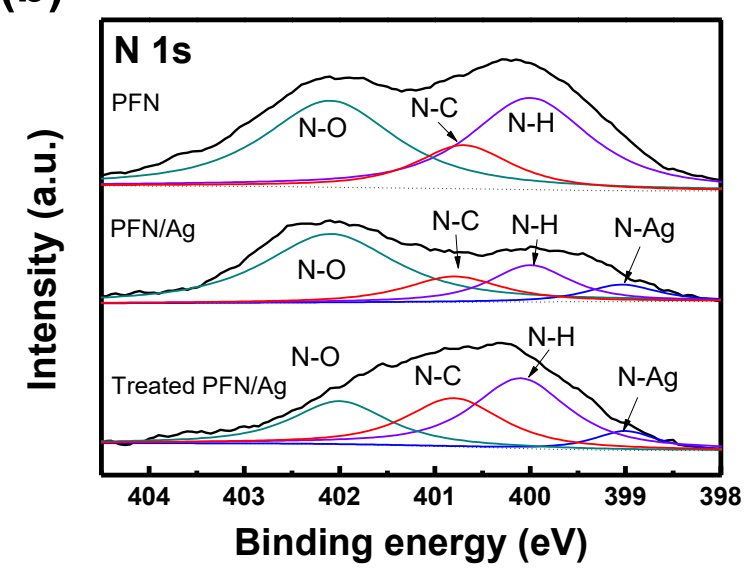


(c)
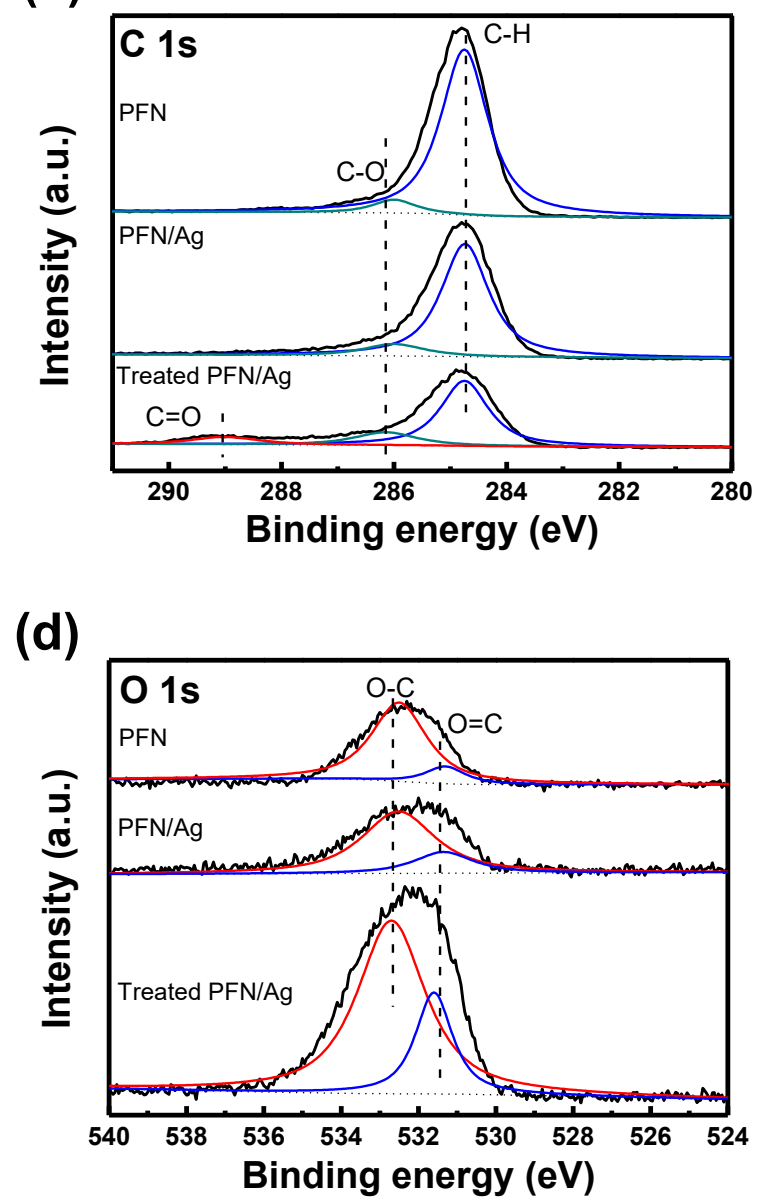

Figure 3. High-resolution XPS spectra of (a) Ag 3d, (b) N 1s, (c) C 1s and (d) O 1s core level of bare Ag, PFN, untreated PFN/Ag and plasma-treated PFN/Ag films. For analyzing the chemical bonding states, the spectra are fitted using a combination of Gaussian and Lorentzian functions.

To explore the microscopic topography, three different electrodes are imaged with atomic force microscopy (AFM), surface scanning electron microscopy (SEM) and conductive AFM (C-AFM). As shown in Figure 4a-c, the root mean squares (RMS) roughness values are 2.62, 2.00 and $1.30 \mathrm{~nm}$ for bare $\mathrm{Ag}(10 \mathrm{~nm})$, untreated PFN/Ag $(10 \mathrm{~nm})$ and plasma-treated PFN/Ag $(10 \mathrm{~nm})$ electrodes, respectively. Compared to 
the bare $\mathrm{Ag}$, the reduced RMS value of the untreated PFN/Ag indicates that the insertion of a thin layer of PFN can improve the uniformity of the ultrathin Ag film. The lowest RMS value of the plasma-treated PFN/Ag film demonstrates a better contact between PFN surface and Ag film. To confirm the observations with AFM, a more clearly distinguishable morphology is recorded by SEM. As shown in Figure 4d-f, when $\mathrm{Ag}$ atoms are directly deposited on substrates, a large number of $\mathrm{Ag}$ nanoaggregates are formed with very clear gullies between each other, which can produce strong plasmon resonance, leading to the decrease of light transmittance (Figure 2a). The aggregated Ag nanoclusters are suppressed when the PFN layer is introduced as a seed layer, since the functional amine groups endow the stronger interaction between PFN and $\mathrm{Ag}$ atoms than $\mathrm{Ag}-\mathrm{Ag}$ atoms. Remarkably, the gullies are connected and a continuous Ag network is formed by UV/ozone plasma treatment originating from more generation of polar groups (Figure S3). Furthermore, the corresponding perpendicular current distribution of different electrodes is obtained with C-AFM (Figure 4g-i). For the bare Ag electrode, low current is produced in the whole region except a few isolated islands with the high current. For the untreated PFN/Ag electrode, since Ag islands are partially connected, the conductive area is enlarged compared to the bare Ag electrode. The current intensity further becomes stronger and the current distribution is more uniform for UV/ozone plasma-treated PFN/Ag electrode due to favorable connections among Ag nanoparticles. It can be seen that the changes in C-AFM images are perfectly reflected in the sheet resistance values of three films (Figure 2b), verifying UV/ozone plasma treatment is an effective 
method for enhancing electrical performances of polymer/metal hybrid electrodes.
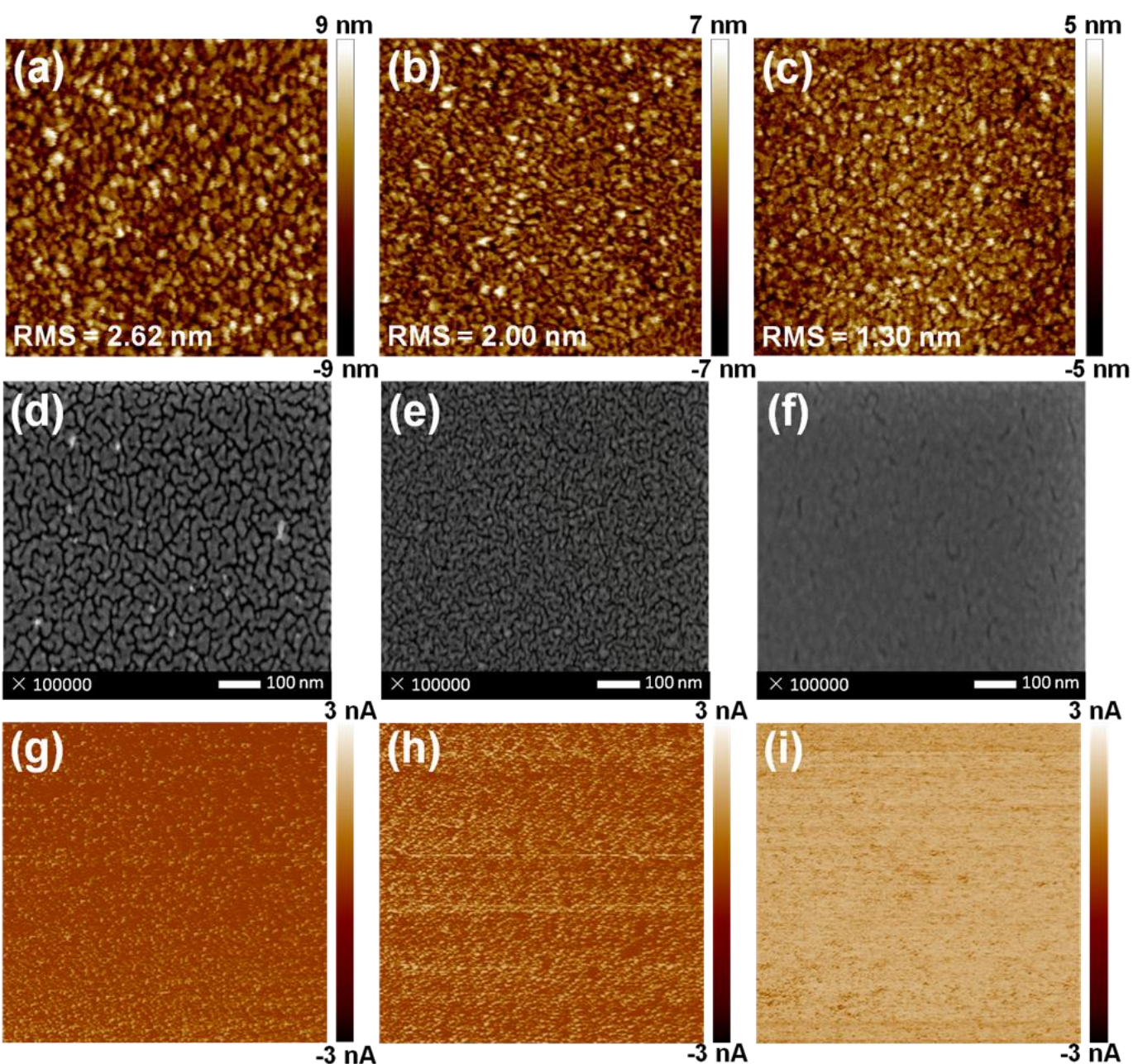

Figure 4. AFM, SEM and C-AFM images of (a, d, g) bare Ag (10 nm), (b, e, h) untreated PFN/Ag (10 nm) and (c, f, i) plasma-treated PFN/Ag (10 nm) electrodes, respectively (AFM image size: $1 \mu \mathrm{m} \times 1 \mu \mathrm{m}$, SEM bar $=100 \mathrm{~nm}$, C-AFM image size: $5 \mu \mathrm{m} \times 5 \mu \mathrm{m})$.

\subsection{Performance of semitransparent PSCs based on PFN/Ag electrodes}

To evaluate whether the optical and electrical properties of hybrid PFN/Ag electrodes are good enough for organic electronics, three different types of inverted ITO-free 
semitransparent PSCs are fabricated in comparison to the controlled sample of ITO-based semitransparent PSCs with the structure of ITO/PFN/BHJ/PEDOT:PSS.

Sample 1 (S1): Ag/PFN/BHJ/PEDOT:PSS (illuminated from PEDOT:PSS)

Sample 2 (S2): Untreated PFN/Ag/PFN/BHJ/PEDOT:PSS (illuminated from PEDOT:PSS)

Sample 3 (S3): Plasma-treated PFN/Ag/PFN/BHJ/PEDOT:PSS (illuminated from PEDOT:PSS)

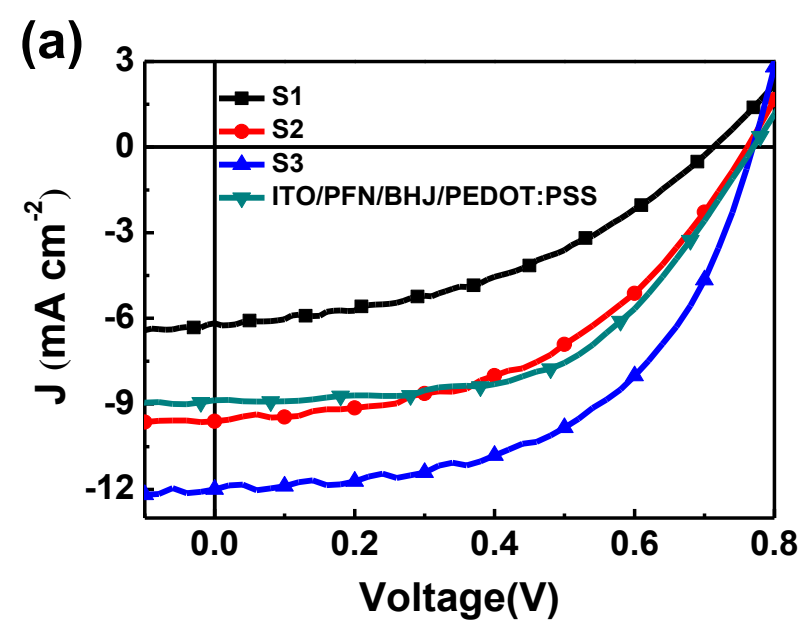

(b)

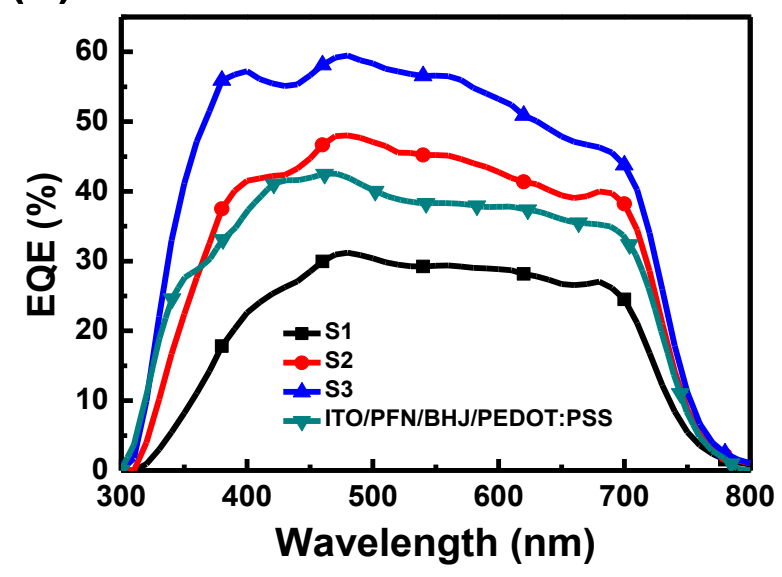

Figure 5. (a) $J-V$ and (b) EQE curves of $\mathrm{S} 1, \mathrm{~S} 2, \mathrm{~S} 3(\mathrm{Ag}=12 \mathrm{~nm}$ ) and ITO-based device illuminated from PEDOT:PSS. 
Figure 5a presents the current density versus voltage $(J-V)$ of semitransparent PSCs under simulated AM 1.5G illumination. The deduced photovoltaic parameters of all devices including the short-circuit current $\left(J_{\mathrm{SC}}\right)$, open circuit voltage $\left(V_{\mathrm{OC}}\right)$, fill factor (FF) and PCE are summarized in Table 1. S1 shows a low $J_{\mathrm{SC}}$ of $6.17 \mathrm{~mA} \mathrm{~cm}{ }^{-2}$ and a low PCE of $1.87 \%$ due to the unnecessary optical loss and high $\mathrm{R}_{\text {sheet, }}$ which also influence $V_{\mathrm{OC}}$ to a value of $0.71 \mathrm{~V}^{2}$ It is noticed that incorporating $\mathrm{PFN}$ to $\mathrm{Ag}$ electrode makes S2 own a higher $J_{\mathrm{SC}}$ of $9.61 \mathrm{~mA} \mathrm{~cm}^{-2}, V_{\mathrm{OC}}$ of $0.76 \mathrm{~V}$ and PCE of $3.34 \%$ than S1. Furthermore, UV/ozone plasma treatment makes S3 present the highest $V_{\mathrm{OC}}$ of $0.77 \mathrm{~V}, J_{\mathrm{SC}}$ of $12.02 \mathrm{~mA} \mathrm{~cm} \mathrm{~cm}^{-2}$ and PCE of $5.02 \%$. For the controlled semitransparent device with ITO, a low $J_{\mathrm{SC}}$ of $8.87 \mathrm{~mA} \mathrm{~cm}^{-2}$ and a moderate PCE of $3.72 \%$ are obtained, revealing that low-cost UV/ozone plasma-treated PFN/Ag electrode is most effective for semitransparent PSCs. Moreover, the similar trend is observed in $J-V$ characteristics of solar cells illuminated from $\mathrm{Ag}$ side (as shown in Figure S4). Figure 5b presents the external quantum efficiency (EQE) curves of the corresponding semitransparent PSCs. All of the devices show a broad photo response ranging from 300 to $800 \mathrm{~nm}$ and S3 shows the highest EQE value. Particularly, the lower EQE of the controlled ITO-based semitransparent PSC than S2 and S3 is attributed to the lower light reflection of ITO in the long wavelength region, which leads to less absorption of the active layer (Figure S5). The reflectance spectrum of PFN/Ag shows a noticeably better match to the absorption spectrum of the active layer. Thus the improved photocurrent response in S3 is attributed to a microcavity-induced light trapping effect originating from the effective internal light 
reflection between PFN/Ag and PEDOT:PSS in conjunction with good electrode conductivity. Furthermore, to illustrate the performance dependence on the $\mathrm{Ag}$ thickness, different PSCs with 8, 10 and $14 \mathrm{~nm}$ thick Ag are also investigated. The $J-$ $V$ curves and concrete device performances are shown in Figure S6 and Table S2. It is noteworthy that device $\mathrm{S} 1$ with the bare $\mathrm{Ag}(8 \mathrm{~nm})$ electrode and device $\mathrm{S} 2$ with the untreated PFN/Ag $(8 \mathrm{~nm})$ electrode do not work because the $\mathrm{R}_{\text {sheet }}$ values of these electrodes are extremely big. In comparison, device S3 with the plasma-treated PFN/Ag $(8 \mathrm{~nm})$ electrode exhibits a $V_{\mathrm{OC}}$ of $0.75 \mathrm{~V}$ and a PCE of $2.75 \%$ due to the efficient $\mathrm{R}_{\text {sheet }}$ decrease of hybrid electrode (about $70.2 \mathrm{Ohm} \mathrm{sq}^{-1}$ ), proving the effectiveness of UV/zone plasma treatment. It is found that the tendency under different Ag thicknesses is the same, that is, the plasma-treated PFN/Ag electrode can greatly maximize the semitransparent device efficiency. Although increasing $\mathrm{Ag}$ thickness from 8 to $14 \mathrm{~nm}$ can notably improve $J_{\mathrm{SC}}$ and PCE values, the corresponding device transparency is firstly increased and then decreased with a maximal transmittance at the Ag thickness of $10 \mathrm{~nm}$, which will be discussed in part 2.5. This phenomenon can also be found when semitransparent PSCs are illuminated from the Ag side (Figure S4 and Table S1). For exploring the superiority of the PFN/Ag hybrid electrode, the control device with the opaque Ag was also investigated. As depicted in Figure S7, a high $J_{\mathrm{SC}}$ of $15.96 \mathrm{~mA} \mathrm{~cm} \mathrm{~cm}^{-2}$ is achieved based on the opaque Ag cathode, resulting in a high PCE of 7.59\%. It can be seen that the PCE ratio of plasma-treated PFN/Ag-based PSCs and opaque one is varied from 36 to $73 \%$ when changing $\mathrm{Ag}$ thickness from 8 to $14 \mathrm{~nm}$. Taking into account the good 
transmittance values of PFN/Ag-based semitransparent PSCs (see Part 2.5), the efficiency loss should be very less when Ag thickness is bigger than $10 \mathrm{~nm}$.

Table $1 V_{\mathrm{OC}}, J_{\mathrm{SC}}, \mathrm{FF}, \mathrm{PCE}$ and $\mathrm{AVT}$ of devices with different electrodes under illumination of AM 1.5G (100 $\left.\mathrm{mW} \mathrm{cm}^{-2}\right)$. Over 20 devices are tested for each average value.

\begin{tabular}{cccccc}
\hline Type & $V_{\mathrm{OC}}(\mathrm{V})$ & $\mathrm{FF}$ & $J_{\mathrm{SC}}\left(\mathrm{mA} \mathrm{cm}^{-2}\right)$ & $\mathrm{PCE}_{\max }\left[\mathrm{PCE}_{\mathrm{ave}}\right](\%)$ & $\mathrm{AVT}(\%)$ \\
\hline $\mathrm{S} 1^{\mathrm{a}}$ & 0.71 & 42.5 & 6.17 & $1.87[1.67]$ & 21.2 \\
$\mathrm{~S}^{\mathrm{a}}$ & 0.76 & 45.7 & 9.61 & $3.34[3.21]$ & 23.7 \\
$\mathrm{~S} 3^{\mathrm{a}}$ & 0.77 & 53.9 & 12.02 & $5.02[4.92]$ & 27.8 \\
$\mathrm{ITO}$ & 0.77 & 54.5 & 8.87 & $3.72[3.61]$ & 38.2 \\
\hline
\end{tabular}

PCE $E_{\max }$ : maximum power conversion efficiency; $\mathrm{PCE}_{\mathrm{ave}}$ : average power conversion efficiency. ${ }^{\mathrm{a}} \mathrm{Ag}=12 \mathrm{~nm}$.

To determine whether the PFN/Ag electrode can provide the uniform and pinhole-free photocurrent distribution over the device surface, the high resolution laser beam induced current (LBIC) images of three types of semitransparent PSCs are recorded. ${ }^{54-56}$ As shown in Figure 6, the microscopic photocurrent images are well in accordance with the macroscopic $J_{S C}$ values. Compared to S1 and S2, S3 exhibits the highest photocurrent intensity due to the finest ultrathin Ag conducting network as discussed in $\mathrm{R}_{\text {sheet }}$ and morphology analysis. Thus it can be concluded that UV/ozone plasma-treated PFN/Ag electrode is a very promising alternative to ITO for 
semitransparent solar cells.
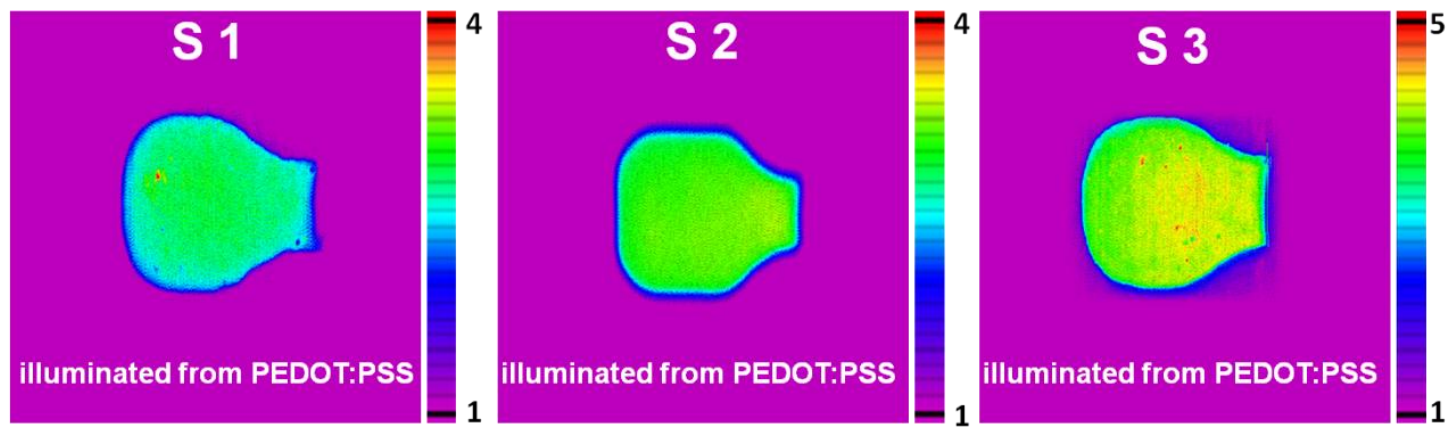

Figure 6. LBIC images of $\mathrm{S} 1, \mathrm{~S} 2$, and $\mathrm{S} 3(\mathrm{Ag}=12 \mathrm{~nm})$ (image dimensions: $6 \mathrm{~mm} \times 6$ $\mathrm{mm})$.

\subsection{Optical field modulation ability of PFN/Ag electrodes in semitransparent PSCs}

To further illustrate the optical field modulation ability of PFN/Ag electrodes, the photon absorption rate profiles (300-800 $\mathrm{nm}$ ) of the semitransparent PSCs based on ITO or PFN/Ag (12 nm) electrodes are calculated and compared. As shown in Figure 7a,b, the photon absorption rate profile of PFN/Ag-based semitransparent PSCs with the biggest value located at the middle of the active layer is entirely different from that of ITO-based semitransparent PSCs at the PEDOT:PSS/active layer interface, which endows PFN/Ag-based PSCs with more carriers generation due to the decrease of exciton quenching by electrodes. ${ }^{57}$ The integrated photon flux density in PFN/Ag-based semitransparent PSCs with a favorable photon distribution profile is $8.03 \times 10^{20} \mathrm{~m}^{-2} \mathrm{~s}^{-1}$, increased by $27.3 \%$ compared to the weaker microcavity ITO-based semitransparent PSCs $\left(6.31 \times 10^{20} \mathrm{~m}^{-2} \mathrm{~s}^{-1}\right)$. It can be seen that the experimental $J_{\mathrm{SC}}$ of $\mathrm{S} 3$ is increased by $35.6 \%$ compared to the ITO-based device (Table 1), which is bigger than $27.3 \%$ from the integrated photon flux density. The reason should be 
attributed to the fine photon distribution in PFN/Ag-based devices, leading to the fact that the increase of $J_{\mathrm{SC}}$ is larger than that expected from the integrated photon flux density. In order to analyze the absorption distribution of photons at different wavelengths within the device, the corresponding exciton generation rate $(G(\lambda))$ is investigated. Figure 7c,d show the equal-scale contour plot of $G(\lambda)$ in devices on the assumption that excitons are generated over the entire layers. Compared to the ITO electrode, more excitons at different wavelengths are efficiently generated in the PFN/Ag-based device, leading to the enhancement of photocurrent. It should be pointed out that ITO decreases the optical interference in device due to its high transmittance and low reflectance. ${ }^{58}$ The wavelength-dependent strong interference in the PFN/Ag-based device implies that the non-absorbed photons in the first path can be reflected and reabsorbed in the second and subsequent paths. Moreover, it can be seen that the power dissipation in the wavelength range from 340 to $400 \mathrm{~nm}$ appears for the 45-nm-thick PFN layer, which should be eliminated as far as possible by selecting the higher bandgap polymer as the optical spacer in the future. Overall, the simulation results confirm that hybrid PFN/Ag electrode has a favorable effect on regulating light field distribution to take full advantage of incident light. 
(a)

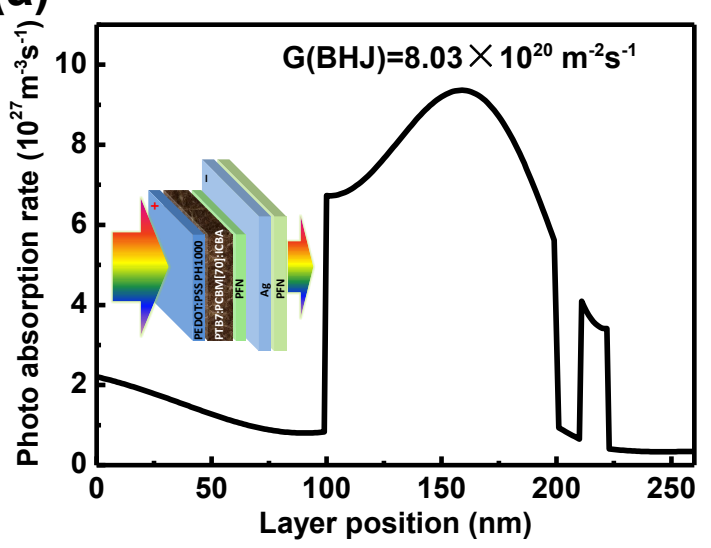

(b)
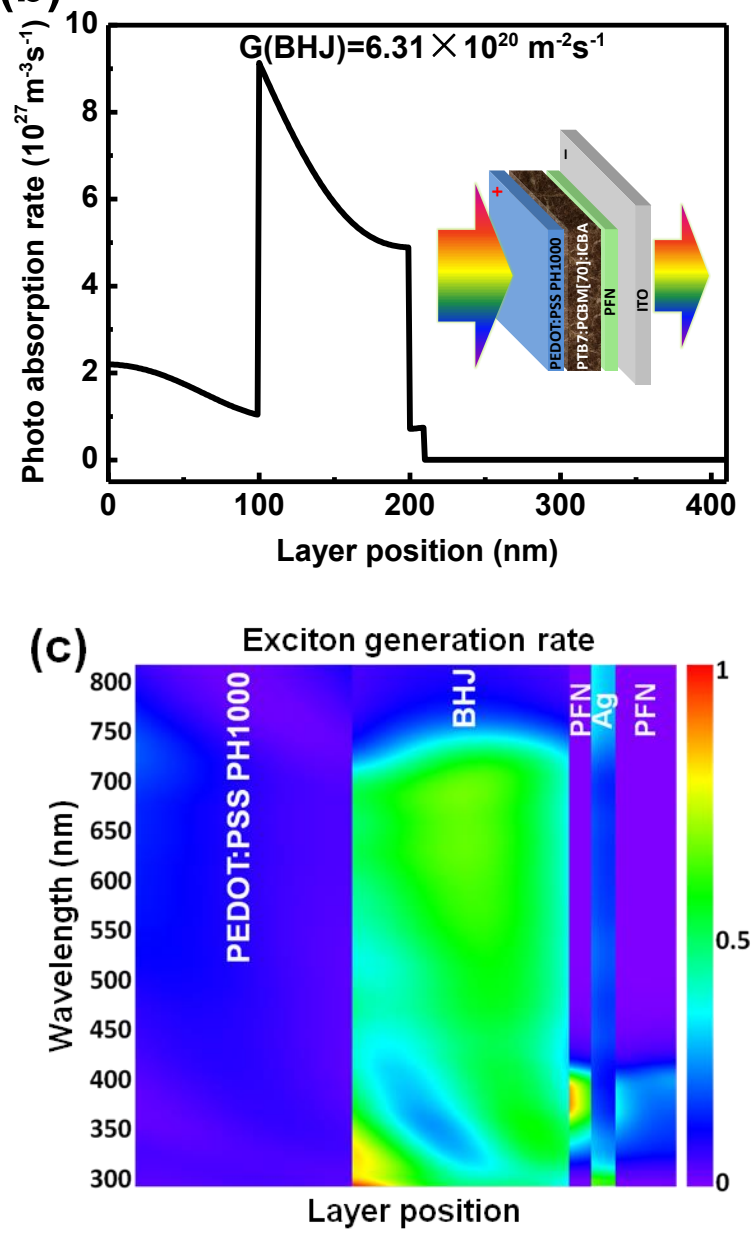


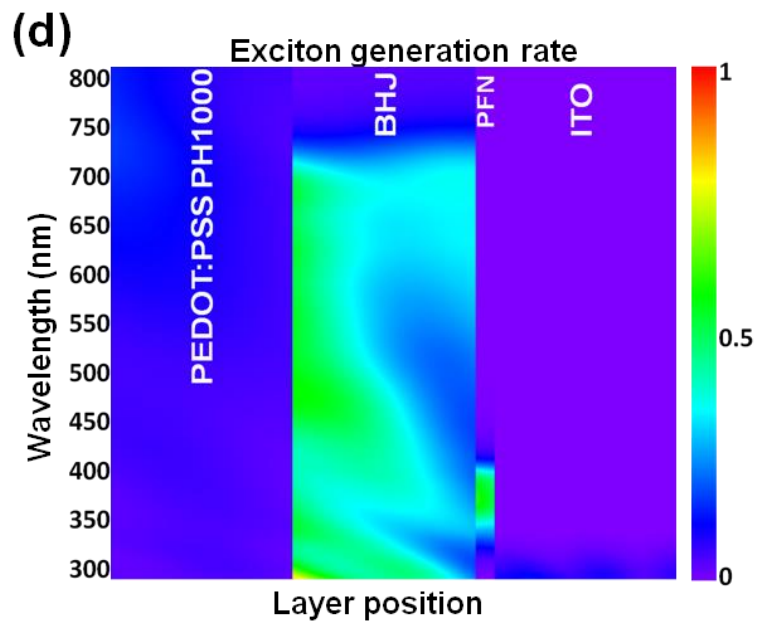

Figure 7. Simulations of $(a, b)$ photon absorption rate profiles and (c, d) exciton generation rate with the wavelength range from 300 to $800 \mathrm{~nm}$ in semitransparent PSCs using PFN/Ag (12 nm) and ITO electrodes illuminated from PEDOT:PSS.

2.5. Enhanced AVT with eliminated plasmonic absorption of Ag nanoparticles For power-generating window applications, an AVT of $25 \%$ is required so a certain photon loss is unavoidable, leading to the tradeoff between device efficiency and transparency. ${ }^{59,60}$ Figure 8 shows the total experimental and simulated transmittance spectra of three types of ITO-free semitransparent PSCs with the 12-nm-thick Ag. Compared to S1, the AVT of S2 increases in the wavelength range from 380 to 780 $\mathrm{nm}(21.2 \%$ vs. $23.7 \%)$. Especially the AVT of S3 is as high as $27.8 \%$, increased by $31.1 \%$ compared to that of $\mathrm{S} 1$, which exceeds the commercial benchmark of $25 \%$ for window applications. The device transmittance can also be predicted by means of optical simulations (Figure 8), which ignore the plasmonic absorption of photons by Ag nanoparticles. It can be seen that there exists a big difference between the experimental and simulated transmittance spectra for $\mathrm{S} 1$; however, the deviation 
between experimental and simulated transmittance spectra for S2 becomes smaller due to the effective interaction of Ag atoms and PFN molecules. Surprisingly, this offset is nearly disappeared for S3, indicating that a uniform, continuous and high-transmittance ultrathin $\mathrm{Ag}$ electrode is formed with a vanished plasmonic absorption of Ag nanoaggregates. The measured device transmittance spectra using 8, 10 and 14-nm-thick Ag are presented in Figure S8. The corresponding AVT values of 22.5, 26.4 and $31.1 \%$ for three types of semitransparent devices with $10 \mathrm{~nm} \mathrm{Ag}$ are highest compared with other semitransparent PSCs with 8, 12 and $14 \mathrm{~nm} \mathrm{Ag} \mathrm{(Table}$ $\mathrm{S} 2$ ), indicating the percolation threshold thickness of $\mathrm{Ag}$ is $10 \mathrm{~nm}$. It is observed that with increasing the Ag thickness from 8 to $14 \mathrm{~nm}$, the difference of AVT between S1 and $\mathrm{S} 3$ is reduced due to the suppression of $\mathrm{Ag}$ plasmonic absorption. The results show that S3 with the plasma-treated PFN/Ag $(12 \mathrm{~nm})$ electrode exhibits the best device performance with a higher AVT than $25 \%$ in the wavelength range from 380 to $780 \mathrm{~nm}$.

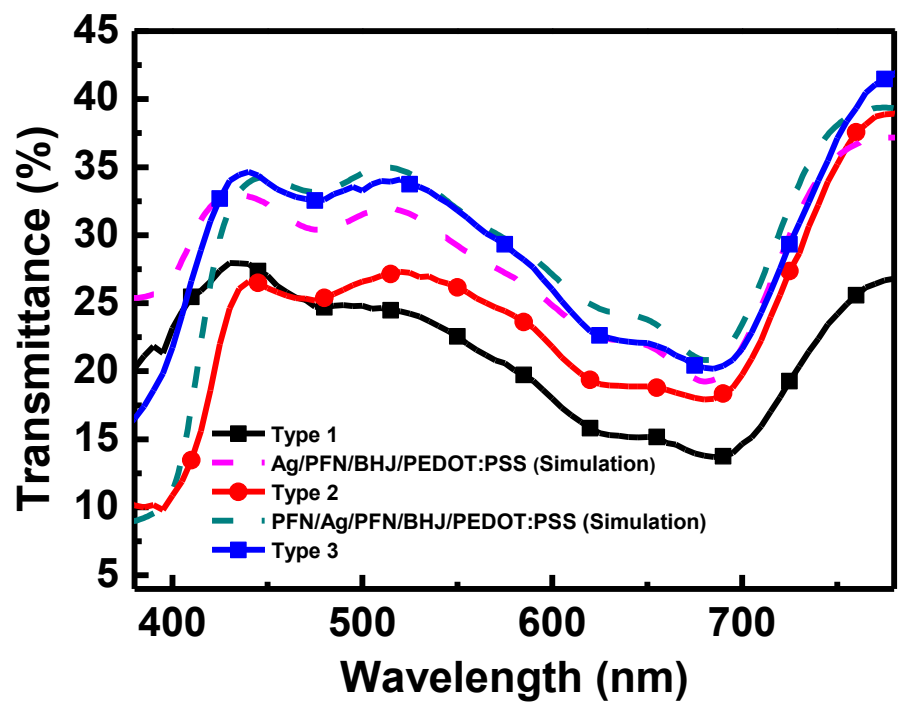

Figure 8. Experimental transmittance spectra of S1, S2 and $S 3$ with the 12-nm-thick 
Ag in comparison to simulated transmittance spectra with/without PFN (45 nm).

\subsection{Universality of UV/ozone plasma treatment}

For verifying the universality of UV/ozone plasma treatment technique, a hole transport conjugated polymer poly(vinylcarbazole) (PVK) is also introduced as the seed layer for Ag electrodes (Figure S9). Guo et al. found PVK/Ag/PVK multilayer electrodes without treatment have excellent opto-electrical properties. ${ }^{43}$ However, in this work, compared with the bare Ag with the $\mathrm{R}_{\text {sheet }}$ of $483 \mathrm{kOhm} \mathrm{sq}^{-1}$, the $\mathrm{R}_{\text {sheet }}$ of the untreated PVK/Ag $(10 \mathrm{~nm})$ is still very high $\left(19.3 \mathrm{kOhm} \mathrm{sq}{ }^{-1}\right)$, which is much bigger than that of the untreated PFN/Ag (147.5 $\mathrm{Ohm} \mathrm{sq}^{-1}$ ), indicating PVK has weaker seed layer function than PFN with the functional amine groups. Moreover, the optical AVT values of bare Ag and untreated PVK/Ag electrodes are nearly the same (37.6\% vs. $37.8 \%$ ), which is slightly lower than PFN/Ag (37.6\% vs. 38.9\%). It should be mentioned that there does not exist optimum thickness of the PVK layer based on the calculated device transmittance, viz., PVK cannot effectively adjust the light field, resulting from the low refractive index of PVK (Figure S9b). ${ }^{61}$ When UV/ozone plasma treatment is performed on the PVK surface, the $\mathrm{R}_{\text {sheet }}$ of PVK/Ag $(10 \mathrm{~nm})$ is significantly reduced from $19.3 \mathrm{kOhm} \mathrm{sq}^{-1}$ to $45.3 \mathrm{Ohm} \mathrm{sq}^{-1}$ and the transmittance is improved from 37.8 to $50.1 \%$. Furthermore, the best semitransparent PSC based on the plasma-treated PVK/Ag $(12 \mathrm{~nm})$ hybrid electrode shows a PCE of $4.25 \%$ and an AVT of $29.7 \%$ (Figure S10). The simulated transmittance is consistent with the experimentally measured transmittance for the plasma-treated PVK/Ag (12 nm) 
semitransparent device, illuminating the validity of the calculation method (Figure S10c). In short, it can be concluded that UV/ozone plasma treatment on the surface of different polymers has a promoting influence on enhancing semitransparent device performances, especially for the water/alcohol-soluble polymer with functional amine groups, demonstrating the effectiveness and universality of polymer/metal hybrid electrodes.

\section{CONCLUSION}

In summary, a novel high-quality plasma-treated water/alcohol-soluble conjugated PFN/Ag hybrid electrode is developed as an alternative to expensive ITO. The superior optical and electrical properties of PFN/Ag electrode are achieved due to the dual functions of a seed layer and an optical spacer of PFN assisted by UV/ozone plasma treatment. The atom interaction between PFN and Ag is analyzed by XPS and the morphology is investigated by AFM, SEM, C-AFM and LBIC. A high efficiency of 5.02\% is successfully obtained in ITO-free semitransparent PSCs with an AVT of 28\% based on PTB7:PCBM[70]:ICBA, satisfying the hybrid electrode well-suited to BIPV systems. The PCE is greatly increased by 35\% compared to ITO-based semitransparent PSC mainly due to a more reasonable optical field distribution originating from the high wavelength-dependent reflectance of hybrid electrode, which is theoretically simulated by means of photon absorption rate profile, exciton generation rate and transmittance. Promisingly other polymer like PVK with

UV/ozone plasma treatment is also successfully explored in hybrid polymer/metal 
electrodes, illustrating the universality and effectiveness of the method. This work not only demonstrates a superior polymer/metal electrode than ITO, but also provides insights into a novel electrode design for optimizing semitransparent PSCs.

\section{EXPERIMENTAL SECTION}

\subsection{Materials}

PTB7 and PCBM[70] were purchased from 1-Material Inc. and Solenne Inc., respectively. PEDOT:PSS (Clevios PH1000) solution was mixed with 5\% dimethyl sulfoxide (DMSO) (Alfa Aesar 99.9\%) to improve the conductivity and $0.5 \%$ surfactant (FS-30) to improve wettability. ${ }^{62,63} \mathrm{PFN}$ was purchased from 1-Material Inc. ICBA was synthesized in our laboratory. ${ }^{62}$ Ternary solute system of PTB7: PCBM[70]: ICBA was dissolved in the ternary solvent system of chlorobenzene: 1,8-diiodooctane: 1-chloronaphthalene ( $94: 3: 3$ by volume) for maximizing the active layer photon-to-electron generation. The energy level of ICBA matches energy alignment of PTB7:PCBM[70] blends, providing a new pathway for charge transfer from PTB7 to the PCBM[70]:ICBA alloy. ${ }^{62}$ The blending ratio of PTB7:PCBM[70]:ICBA was 1:1.5:0.25 with a concentration of $25 \mathrm{mg} / \mathrm{ml}$. All reagents and metals were purchased from Alfa, Dupont, GCRF, and used without further purification.

\subsection{Device fabrication}

The inverted ITO-free semitransparent PSCs were fabricated on glass substrates 
which were ultrasonically cleaned with acetone, alkaline lotion, deionized water and isopropanol, respectively. A 45-nm-thick PFN layer was spin-coated onto the glass substrate and then treated by UV/ozone plasma at different powers for $60 \mathrm{~s}$. To verify the effect of PFN/Ag hybrid electrodes with UV/ozone plasma treatments, the bare $\mathrm{Ag}$ and PFN/Ag without surface treatments were also analyzed. Ag was thermally evaporated under the vacuum degree of $4 \times 10^{-4} \mathrm{~Pa}$. Then, a thin 10 -nm-thick electron transport layer of PFN was spin-coated onto the surface of Ag. The 90-100 nm PTB7: PCBM[70]: ICBA active layer was spin-coated on the surface of PFN layer. The PEDOT:PSS solution was spin-coated on the surface of active layer with a thickness of $100 \mathrm{~nm}$ in air, followed by annealing at $60{ }^{\circ} \mathrm{C}$ for $60 \mathrm{~s}$ to remove any residual water. Finally, the devices were encapsulated using UV-curing adhesive and clean glass lid. The effective active area was $4 \mathrm{~mm}^{2}$ determined by a patterned mask.

\subsection{Measurements and characterization}

Transmittance and reflectance were performed with different illumination directions recorded using a Shimadzu UV-2550 UV-visible spectrophotometer. The sheet resistances were measured using a custom-built four-point probe system with a Keithley 2400 source measure unit. The film thickness was measured by a surface profiler (XP-2, Ambios). The high resolution XPS spectra were measured by a photoelectron spectrometer (AXIS ULTR DLD, Kratos, England). Contact angles using water as the testing liquid were determined on top of the solid active films by a drop shape analyzer DSA100 instrument. The film topography was investigated by 
AFM (Bioscope Catalyst Nanoscope-V), SEM (ULTRA55, Zeiss) and C-AFM (CSPM5500). The $J-V$ characteristics were measured using a Keithley 2400 source meter under an illumination of AM $1.5 \mathrm{G}$ solar simulator with an intensity of $100 \mathrm{~mW}$ $\mathrm{cm}^{-2}$ (Sun 2000 Solar Simulator, Abet Technologies, Inc.). The EQE data were obtained by a QE-R test system from Enli Technology Company (Taiwan). The light intensity of the solar simulator was calibrated by a standard silicon photo-diode (NIMMS1101, National Institute of Metrology, China), which was also used as the reference solar cell in the EQE measurement for obtaining a transformation coefficient compared to the $J-V$ curve. The thickness of Ag films was monitored by a quartz crystal thickness/ratio monitor (model: STM-100/MF, Sycon). The LBIC was imaged using a plused laser diode beam at $405 \mathrm{~nm}$ that scanned the cell's surface with an image resolution of $50 \mu \mathrm{m}$ (LSD4, Enli). Optical constants ( $n$ and $k$ ) were measured using a Horiba Jobin Yvon AUTO SE ellipsometer. Optical calculations are based on transfer matrix modeling compiled with MATLAB, which is widely used in optics to analyze the propagation of electromagnetic waves through a stratified medium. ${ }^{64,65}$

\section{ASSOCIATED CONTENT}

\section{Supporting Information}

The Supporting Information is available free of charge on the ACS Publications website at DOI: 
Stimulated transmittance images of polymer/Ag electrodes; optical transmittance spectra of hybrid electrodes; water contact angles; $J-V$ and EQE of S1, S2 and S3 devices from the Ag side; $J-V$ of devices with different Ag thicknesses from two sides; reflectance spectra of electrodes and absorption spectrum of the active layer; $J-V$, EQE and transmittance spectra of devices with PVK/Ag electrodes. (PDF)

\section{AUTHOR INFORMATION}

\section{Corresponding Authors}

${ }^{*}$ Email: thlt@jnu.edu.cn

${ }^{*}$ Email: fengling.zhang@liu.se

\section{ORCID}

Hou Lintao: 0000-0002-4358-3862

Zhang Fengling: 0000-0002-1717-6307

\section{ACKNOWLEDGEMENTS}

The authors are grateful to the NSFC Project $(61774077,61274062,11204106)$, the Guangzhou Science and Technology Plan Project and the Fundamental Research Funds for the Central Universities for financial support. F.Z. acknowledges funding from Swedish Research Council (VR 621-2013-5561) and financial support to visiting professor from Jinan University. Furthermore, we express our gratitude to Dr. Xianfa Zhang of Heilongjiang University for expert assistance with XPS analysis.

\section{REFERENCES}


(1) He, Z.; Xiao, B.; Liu, F.; Wu, H.; Yang, Y.; Xiao, S.; Wang, C.; Russell, T. P.; Cao, Y. Single-junction Polymer Solar Cells with High Efficiency and Photovoltage. Nat. Photonics 2015, 9, 174-179.

(2) Zhang, F.; Inganäs, O.; Zhou, Y.; Vandewal, K. Development of PolymerFullerene Solar Cells. Natl. Sci. Rev. 2016, 3, 222-239.

(3) Li, G.; Zhu, R.; Yang, Y. Polymer Solar Cells. Nat. Photonics 2012, 6, 153-161.

(4) Krebs, F. C. Fabrication and Processing of Polymer Solar Cells: A Review of Printing and Coating Techniques. Sol. Energ. Mat. Sol. C. 2009, 93, 394-412.

(5) Dyer, A. L.; Bulloch, R. H.; Zhou, Y.; Kippelen, B.; Reynolds, J. R.; Zhang, F. A Vertically Integrated Solar-Powered Electrochromic Window for Energy Efficient Buildings. Adv. Mater. 2014, 26, 4895-4900.

(6) Shrotriya, V.; Wu, E. H.-E.; Li, G.; Yao, Y.; Yang, Y. Efficient Light Harvesting in Multiple-Device Stacked Structure for Polymer Solar Cells. Appl. Phys. Lett. 2006, $88,064104$.

(7) Long, Y.; Shen, L.; Ruan, S.; Yu, W.; Wang, Y.; Zeng, Q.; Luo, J. Top-to-Bottom Optimization of the Optical Performance of the Tandem Organic Solar Cells with Thin Metal Film as Interlayer. Appl. Phys. Lett. 2012, 100, 103304.

(8) Chen, K.-S.; Yip, H.-L.; Salinas, J.-F.; Xu, Y.-X.; Chueh, C.-C.; Jen, A. K.-Y. Strong Photocurrent Enhancements in Highly Efficient Flexible Organic Solar Cells by Adopting a Microcavity Configuration. Adv. Mater. 2014, 26, 3349-3354. 
(9) Ren, X.; Li, X.; Choy, W. C. H. Optically Enhanced Semi-Transparent Organic Solar Cells through Hybrid Metal/Nanoparticle/Dielectric Nanostructure. Nano Energy 2015, 17, 187-195.

(10) Betancur, R.; Romero-Gomez, P.; Martinez-Otero, A.; Elias, X.; Maymó, M.; Martorell, J. Transparent Polymer Solar Cells Employing a Layered Light-Trapping. Architecture. Nat. Photonics 2013, 7, 995-1000.

(11) Kovalenko, A.; Guerrero, A.; Garcia-Belmonte, G. Role of Vertical Segregation in Semitransparent Organic Photovoltaics. ACS Appl. Mater. Interfaces 2015, 7, $1234-1239$.

(12) Yu, W.; Jia, X.; Long, Y.; Shen, L.; Liu, Y.; Guo, W.; Ruan, S. Highly Efficient Semitransparent Polymer Solar Cells with Color Rendering Index Approaching 100 Using One-Dimensional Photonic Crystal. ACS Appl. Mater. Interfaces 2015, 7, 9920-9928.

(13) Zhang, Y.; Peng, Z.; Cai, C.; Liu, Z.; Lin, Y.; Zheng, W.; Yang, J.; Hou, L.; Cao, Y. Colorful Semitransparent Polymer Solar Cells Employing a Bottom Periodic One-Dimensional Photonic Crystal and a Top Conductive PEDOT:PSS Layer. $J$. Mater. Chem. A 2016, 4, 11821-11828.

(14) Guo, F.; Kubis, P.; Stubhan, T.; Li, N.; Baran, D.; Przybilla, T.; Spiecker, E.; Forberich, K.; Brabec, C. Fully Solution-Processing Route toward Highly Transparent Polymer Solar Cells. ACS Appl. Mater. Interfaces 2014, 6, 18251-18257.

(15) Xu, G.; Shen, L.; Cui, C.; Wen, S.; Xue, R.; Chen, W.; Chen, H.; Zhang, J.; Li, H.; Li, Y.; Li, Y. High-Performance Colorful Semitransparent Polymer Solar Cells 
with Ultrathin Hybrid-Metal Electrodes and Fine-Tuned Dielectric Mirrors. Adv. Funct. Mater. 2017, 27, 1605908.

(16) Wilken, S.; Wilkens, V.; Scheunemann, D.; Nowak, R.; Maydell, K.; Parisi, J.; Borchert, H. Semitransparent Polymer-Based Solar Cells with Aluminum-Doped Zinc Oxide Electrodes. ACS Appl. Mater. Interfaces 2015, 7, 287-300.

(17) Wang, W.; Yan, C.; Lau, T. K.; Wang, J.; Liu, K.; Fan, Y.; Lu, X.; Zhan, X. Fused Hexacyclic Nonfullerene Acceptor with Strong Near-Infrared Absorption for Semitransparent Organic Solar Cells with 9.77\% Efficiency. Adv. Mater. 2017, 31, 1701308.

(18) Romero-Gomez, P.; Betancur, R.; Martinez-Otero, A.; Elias, X.; Mariano, M.;

Romero, B.; Arredondo, B.; Vergaz, R.; Martorell, J. Enhanced Stability in Semi-transparent PTB7/PC ${ }_{71} B M$ Photovoltaic Cells. Sol. Energ. Mat. Sol. C. 2015, $137,44-49$.

(19) Guo, W.; Xu, Z.; Zhang, F.; Xie, S.; Xu, H.; Liu, X. Y. Recent Development of Transparent Conducting Oxide-Free Flexible Thin-Film Solar Cells. Adv. Funct. Mater. 2016, 26, 8855-8884.

(20) Jong, H.; Sung-yoon, J.; Christina, P.; Kyung, M. L.; Huiseong, J.; Ji-Yong, P.; Yeong, H. A.; John, C.; Soonil, L. Fully Solution-Processed Semitransparent Organic Solar Cells with a Silver Nanowire Cathode and a Conducting Polymer Anode. ACS Nano 2014, 3, 2857-2863.

(21) Liu, Z.; You, P.; Liu, S.; Yan, F. Neutral-Color Semitransparent Organic Solar Cells with All-Graphene Electrodes. ACS Nano 2015, 9, 12026-12034. 
(22) Schubert, S.; Meiss, J.; Müller-Meskamp, L.; Leo, K. Improvement of Transparent Metal Top Electrodes for Organic Solar Cells by Introducing a High Surface Energy Seed Layer. Adv. Energy Mater. 2013, 3, 438-443.

(23) Yang, L.; Zhang, T.; Zhou, H.; Price, S.; Wiely, B.; You, W. Solution-Processed Flexible Polymer Solar Cells with Silver Nanowire Electrodes. ACS Appl. Mater. Interfaces 2011, 3, 4075-4084.

(24) Emmott, C. J. M.; Urbina, A.; Nelson, J. Environmental and Economic Assessment of ITO-free Electrodes for Organic Solar Cells. Sol. Energ. Mat. Sol. C. 2012, 97, 14-21.

(25) Kumar, A.; Zhou, C. The Race To Replace Tin-Doped Indium Oxide: Which Material Will Win? ACS Nano 2010, 4, 11-14.

(26) Pang, S.; Hernandez, Y.; Feng, X.; Mullen, K. Graphene as Transparent Electrode Material for Organic Electronics. Adv. Mater. 2011, 23, 2779-2795.

(27) Hellstrom, S.; Lee, H.; Bao, Z. Polymer-Assisted Direct Deposition of Uniform Carbon Nanotube Bundle Networks for High Performance Transparent Electrodes. ACS Nano 2009, 3, 1423-1430.

(28) Choi, K.; Park, Y.; Kwon, K.-C.; Kim, J.; Kim, C.; Kim, S.; Hong, K.; Lee, J.-L. Reduced Graphite Oxide-Indium Tin Oxide Hybrid Materials for Use as a Transparent Electrode. J. Electrochem. Soc. 2011, 158, 231-235.

(29) Lee, J.; Connor, S.; Cui, Y.; Peumans P. Solution-Processed Metal Nanowire Mesh Transparent Electrodes. Nano Lett. 2008, 8, 689-692. 
(30) Zhong, C.; Duan, C.; Huang, F.; Wu, H.; Cao, Y. Materials and Devices toward Fully Solution Processable Organic Light-Emitting Diodes. Chem. Mater. 2011, 23, $326-340$.

(31) Min, J.; Bronnbauer, C.; Zhang, Z.-G.; Cui, C.; Luponosov, Y. N.; Ata, I.; Schweizer, P.; Przybilla, T.; Guo, F.; Ameri, T.; Forberich, K.; Spiecker, E.; Bäuerle, P.; Ponomarenko, S. A.; Li, Y.; Brabec, C. Fully Solution-Processed Small Molecule Semitransparent Solar Cells: Optimization of Transparent Cathode Architecture and Four Absorbing Layers. Adv. Funct. Mater. 2016, 26, 4543-4550.

(32) Guo, F.; Zhu, X.; Forberich, K.; Krantz, J.; Stubhan, T.; Salinas, M.; Halik, M.; Spallek, S.; Butz, B.; Spiecker, E.; Ameri, T.; Li, N.; Kubis, P.; Guldi, D.; Matt, G.; Brabec, C. ITO-Free and Fully Solution-Processed Semitransparent Organic Solar Cells with High Fill Factors. Adv. Energy Mater. 2013, 3, 1062-1067.

(33) Schubert, S.; Müller-Meskamp, L.; Leo, K. Unusually High Optical Transmission in Ca:Ag Blend Films: High-Performance Top Electrodes for Efficient Organic Solar Cells. Adv. Funct. Mater. 2014, 24, 6668-6676.

(34) Hutter, E.; Fendler, J. Exploitation of Localized Surface Plasmon Resonance $A d v$. Mater. 2004, 16, 1685-1706.

(35) Barrows, A. T.; Masters, R.; Pearson, A. J.; Rodenburg, C.; Lidzey, D. G. Indium-free Multilayer Semitransparent Electrodes for Polymer Solar Cells. Sol. Energ. Mat. Sol. C. 2016, 144, 600-607.

(36) Hong, K.; Kim, K.; Kim, S.; Lee, I.; Cho, H.; Yoo, S.; Choi, H. W.; Lee, N.-Y.; Tak, Y.-H.; Lee, J.-L. Optical Properties of $\mathrm{WO}_{3} / \mathrm{Ag} / \mathrm{WO}_{3}$ Multilayer as Transparent 
Cathode in Top-Emitting Organic Light Emitting Diodes. J. Phys. Chem. C 2011, 115, $3453-3459$.

(37) Yu, W.; Shen, L.; Meng, F.; Long, Y.; Ruan, S.; Chen, W. Effects of the Optical Microcavity on the Performance of ITO-free Polymer Solar Cells with $\mathrm{WO}_{3} / \mathrm{Ag} / \mathrm{WO}_{3}$ Transparent Electrode. Sol. Energ. Mat. Sol. C. 2012, 100, 226-230.

(38) Shen, L.; Xu Y.; Meng, F.; Li, F.; Ruan, S.; Chen, W. Semitransparent Polymer Solar Cells Using $\mathrm{V}_{2} \mathrm{O}_{5} / \mathrm{Ag} / \mathrm{V}_{2} \mathrm{O}_{5}$ as Transparent Anodes. Org. Electron. 2011, 12, $1223-1226$

(39) Li, F.; Ruan, S.; Xu Y.; Meng, F.; Wang, J; Chen, W.; Shen, L. Semitransparent Inverted Polymer Solar Cells Using $\mathrm{MoO}_{3} / \mathrm{Ag} / \mathrm{WO}_{3}$ as Highly Transparent Anodes. Sol. Energ. Mat. Sol. C. 2011, 95, 877-880.

(40) Chen, Y; Shen, L.; Yu, W.; Long, Y.; Guo, W; Chen, W.; Ruan, S. Highly Efficient ITO-free Polymer Solar Cells Based on Metal Resonant Microcavity Using $\mathrm{WO}_{3} / \mathrm{Au} / \mathrm{WO}_{3}$ as Transparent Electrodes. Org. Electron. 2014, 15, 1545-1551.

(41) Hu, M.; Noda, S.; Komiyama, H. A New Insight Into the Growth Mode of Metals on $\mathrm{TiO}_{2}(11$ 0). Surf. Sci. 2002, 513, 530-538.

(42) Kang, H.; Jung, S.; Jeong, S.; Kim, G.; Lee, K. Polymer-Metal Hybrid Transparent Electrodes for Flexible Electronics. Nat. Commun. 2015, 6, 6503.

(43) Guo, X.; Liu, X.; Lin, F.; Li, H.; Fan, Y.; Zhang, N. Highly Conductive Transparent Organic Electrodes with Multilayer Structures for Rigid and Flexible Optoelectronics. Sci. Rep. 2015, 5, 10569. 
(44) Jeong, S.; Jung, S.; Kang, H.; Lee, D.; Choi, S.-B.; Kim, S.; Park, B.; Yu, K.; Lee, J.; Lee, K. Role of Polymeric Metal Nucleation Inducers in Fabricating Large-Area, Flexible, and Transparent Electrodes for Printable Electronics. Adv. Func. Mater. 2017, 27, 1606842-1606850.

(45) Aleksandrova, M.; Videkov, V.; Ivanova, R.; Singh, A. K.; Thool, G. S. Highly Flexible, Conductive and Transparent PEDOT:PSS/Au/PEDOT:PSS Multilayer Electrode for Optoelectronic Devices. Mater. Lett. 2016, 174, 204-208.

(46) Ham, J.; Lee, J.-L. ITO Breakers: Highly Transparent Conducting Polymer/Metal/Dielectric (P/M/D) Films for Organic Solar Cells. Adv. Energy Mater. 2014, 4, 1400539-1400548.

(47) He, Z.; Zhong, C.; Su, S.; Xu, M.; Wu, H.; Cao, Y. Enhanced Power-Conversion Efficiency in Polymer Solar Cells Using an Inverted Device Structure. Nat. Photonics 2012, 6, 593-597.

(48) Duan, L.; Wang, P.; Yu, X.; Han, X.; Chen, Y.; Zhao, P.; Li, D.; Yao, R. The Synthesis and Characterization of Ag-N Dual-Doped P-Type ZnO: Experiment and Theory. Phys. Chem. Chem. Phys. 2014, 16, 4092-4097.

(49) Back, H.; Kim, G.; Kim, J.; Kong, J.; Kim, T. K.; Kang, H.; Kim, H.; Lee, J.; Lee, S.; Lee, K. Achieving Long-Term Stable Perovskite Solar Cells via Ion Neutralization. Energy Environ. Sci. 2016, 9, 1258-1263.

(50) Li, W.; Kong, C.; Qin, G.; Ruan, H.; Fang, L. P-Type Conductivity and Stability of Ag-N Codoped ZnO Thin Films. J. Alloy. Compd. 2014, 609, 173-177. 
(51) Hong, K.; Kim, K.; Lee, J.-L. Enhancement of Electrical Property by Oxygen Doping to Copper Phthalocyanine in Inverted Top Emitting Organic Light Emitting Diodes. Appl. Phys. Lett. 2009, 95, 213307-213319.

(52) Murakami, T.; Kuroda, S.; Osawa, Z. Dynamics of Polymeric Solid Surfaces Treated with Oxygen Plasma: Effect of Aging Media after Plasma Treatment. $J$. Colloid. Interf. Sci. 1997, 202, 37-44.

(53) Lai, J.; Sunderland, B.; Xue, J.; Yan, S.; Zhao, W.; Folkard, M.; Michael, B. D.; Wang, Y. Study on Hydrophilicity of Polymer Surfaces Improved by Plasma Treatment. Appl. Surf. Sci. 2006, 252, 3375-3379.

(54) Zhang, F.; Jespersen, K. G.; Björström, C.; Svensson, M.; Andersson, M. R.; Sundström, V.; Magnusson, K.; Moons, E.; Yartsev, A.; Inganäs, O. Influence of Solvent Mixing on the Morphology and Performance of Solar Cells Based on Polyfluorene Copolymer/Fullerene Blends. Adv. Funct. Mater. 2006, 16, 667-674.

(55) Krebs, F. C.; Søndergaard, R.; Jørgensen, M. Printed Metal Back Electrodes for R2R Fabricated Polymer Solar Cells Studied Using the LBIC Technique. Sol. Energ. Mat. Sol. C. 2011, 95, 1348-1353.

(56) Lin, Y.; Cai, C.; Zhang, Y.; Zheng, W.; Yang, J.; Wang, E.; Hou, L. T. Study of ITO-free Roll-to-Roll Compatible Polymer Solar Cells Using the One-Step Doctor Blading Technique. J. Mater. Chem. A 2017, 5, 4093-4102.

(57) Chen, F.-C.; Wu, J.-L.; Hung, Y. Spatial Redistribution of the Optical Field Intensity in Inverted Polymer Solar Cells. Appl. Phys. Lett. 2010, 96, 193304-193308. 
(58) Huang, J.; Li, C.-Z.; Chueh, C.-C.; Liu, S.-Q.; Yu, J.-S.; Jen, A. K. Y. 10.4\% Power Conversion Efficiency of ITO-Free Organic Photovoltaics through Enhanced Light Trapping Configuration. Adv. Energy Mater. 2015, 5, 1500406.

(59) Chen, K.-S.; Salinas, J.-F.; Yip, H.-L.; Huo, L.; Hou, J.; Jen, A. K. Y. Semi-Transparent Polymer Solar Cells with 6\% PCE, 25\% Average Visible Transmittance and a Color Rendering Index Close to 100 for Power Generating Window Applications. Energy Environ. Sci. 2012, 5, 9551-9557.

(60) Drolet, N. Organic Photovoltaic: Efficiency and Lifetime Challenges for Commercial Viability, 2012 MRS Spring Meeting \& Exhibit, San Francisco, CA, Moscone West Convention Center, Marriott Marquis, 2012.

(61) Benchaabane, A.; Ben Hamed, Z.; Kouki, F.; Abderrahmane Sanhoury, M.; Zellama, K.; Zeinert, A.; Bouchriha, H. Performances of Effective Medium Model in Interpreting Optical Properties of Polyvinylcarbazole:ZnSe Nanocomposites. J. Appl. Phys. 2014, 115, 134313.

(62) Peng, Z.; Xia, Y.; Gao, F.; Xiong, K.; Hu, Z.; James, D. I.; Chen, J.; Wang, E.; Hou, L. T. A Dual Ternary System for Highly Efficient ITO-Free Inverted Polymer Solar Cells. J. Mater. Chem. A 2015, 3, 18365-18371.

(63) Mahato, S.; Gerling, L. G.; Voz, C.; Alcubilla, R.; Puigdollers, J. High Efficiency ITO-free Hybrid Solar Cell Using Highly Conductive PEDOT:PSS with Co-Solvent and Surfactant Treatments. Mater. Lett. 2017, 186, 165-167.

(64) Chen, C. -C.; Chang, W.-H.; Yoshimura, K.; Ohya, K.; You, J.; Gao, J.; Hong, Z.; Yang, Y. An Efficient Triple-Junction Polymer Solar Cell Having a Power Conversion Efficiency Exceeding 11\%. Adv. Mater. 2014, 26, 5670-5677. 
(65) Schueppel, R.; Timmreck, R.; Allinger, N.; Muller, T.; Furno, M.; Uhrich, C.; Leo, K.; Riede, M. Controlled Current Matching in Small Molecule Organic Tandem Solar Cells Using Doped Spacer Layers. J. Appl. Phys. 2010, 107, 044503.

\section{TOC}
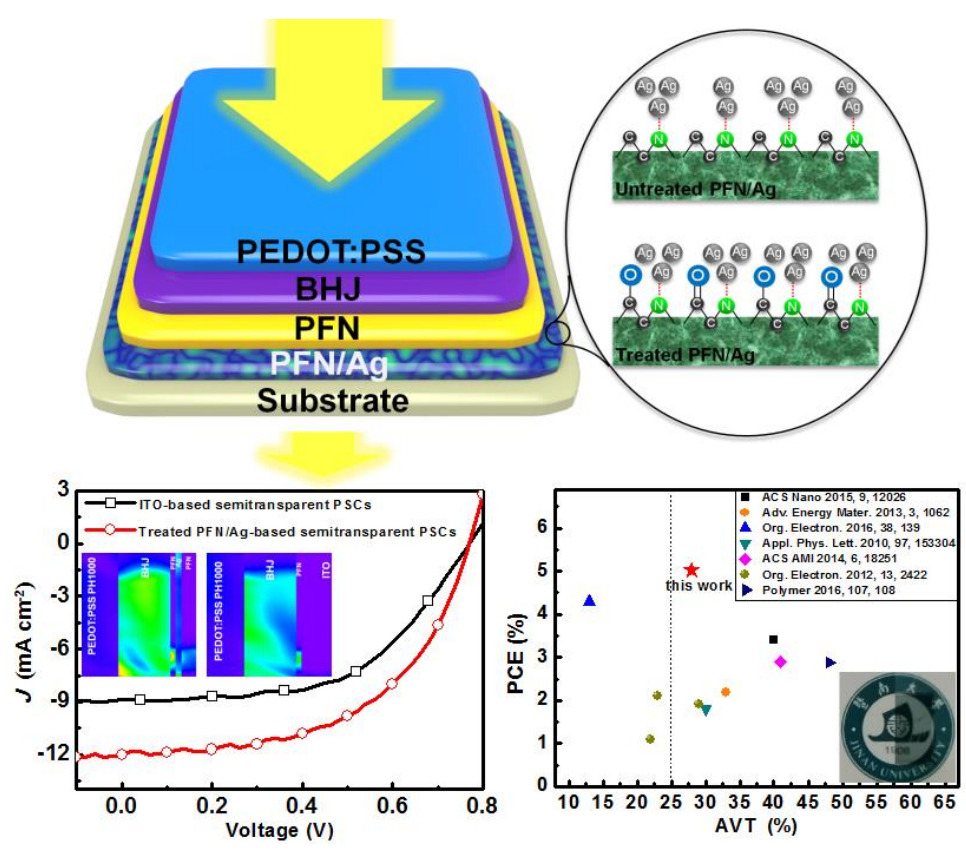